University of Nebraska - Lincoln

DigitalCommons@University of Nebraska - Lincoln

\title{
The relationship between ultrasound measurements and carcass fat thickness and longissimus muscle area in beef cattle
}

\author{
S. P. Greiner \\ lowa State University, sgreiner@vt.edu \\ G. H. Rouse \\ lowa State University \\ D. E. Wilson \\ lowa State University \\ L. V. Cundiff \\ U.S. Meat Animal Research Center, Larry.Cundiff@ars.usda.gov \\ T. L. Wheeler \\ U.S. Meat Animal Research Center, tommy.wheeler@ars.usda.gov
}

Follow this and additional works at: https://digitalcommons.unl.edu/hruskareports

Greiner, S. P.; Rouse, G. H.; Wilson, D. E.; Cundiff, L. V.; and Wheeler, T. L., "The relationship between ultrasound measurements and carcass fat thickness and longissimus muscle area in beef cattle" (2003). Roman L. Hruska U.S. Meat Animal Research Center. 367.

https://digitalcommons.unl.edu/hruskareports/367

This Article is brought to you for free and open access by the U.S. Department of Agriculture: Agricultural Research Service, Lincoln, Nebraska at DigitalCommons@University of Nebraska - Lincoln. It has been accepted for inclusion in Roman L. Hruska U.S. Meat Animal Research Center by an authorized administrator of DigitalCommons@University of Nebraska - Lincoln. 


\title{
The relationship between ultrasound measurements and carcass fat thickness and longissimus muscle area in beef cattle
}

\author{
S. P. Greiner*1, G. H. Rouse*, D. E. Wilson*, L. V. Cundiff $\dagger$, and T. L. Wheeler $\dagger$ \\ *Department of Animal Science, Iowa State University, Ames 50011 and $†$ Roman L. Hruska U.S. Meat Animal \\ Research Center, USDA, ARS, Clay Center, NE 68933
}

\begin{abstract}
Five hundred thirty-four steers were evaluated over a 2-yr period to determine the accuracy of ultrasonic estimates of carcass 12 th-rib fat thickness (CFAT) and longissimus muscle area (CLMA). Within 5 $\mathrm{d}$ before slaughter, steers were ultrasonically measured for 12th-rib fat thickness (UFAT) and longissimus muscle area (ULMA) using an Aloka 500V real-time ultrasound machine equipped with a $17.2-\mathrm{cm}, 3.5-\mathrm{MHz}$ linear transducer. Overall, correlation coefficients between ultrasound and carcass fat and longissimus muscle area were 0.89 and 0.86 , respectively. Correlations for UFAT with CFAT were similar between years (0.86 and 0.90), whereas the relationship between ULMA and CLMA was stronger in yr $1(\mathrm{r}=0.91 ; \mathrm{n}=$ $282)$ than in yr $2(r=0.79 ; n=252)$. Differences between ultrasonic and carcass measurements were expressed on both an actual (FDIFF and RDIFF) and absolute (FDEV and RDEV) basis. Mean FDIFF and RDIFF indicated that ultrasound underestimated CFAT by 0.06 $\mathrm{cm}$ and overestimated CLMA by $0.71 \mathrm{~cm}^{2}$ across both years. Overall mean FDEV and RDEV, which are indi-

cations of the average error rate, were $0.16 \mathrm{~cm}$ and 3.39 $\mathrm{cm}^{2}$, respectively. Analysis of year effects revealed that FDIFF, FDEV, and RDEV were greater $(P<0.01)$ in magnitude in yr 1 . Further analysis of FDEV indicated that leaner $(\mathrm{CFAT}<0.51 \mathrm{~cm})$ cattle were overestimated and that fatter $(\mathrm{CFAT}>1.02 \mathrm{~cm})$ cattle were underestimated with ultrasound. Similarly, steers with small CLMA $\left(<71.0 \mathrm{~cm}^{2}\right)$ were overestimated, and steers with large CLMA $\left(>90.3 \mathrm{~cm}^{2}\right)$ were underestimated. The thickness of CFAT had an effect $(P<0.05)$ on the error of UFAT and ULMA measurements, with leaner animals being more accurately evaluated for both traits. Standard errors of prediction (SEP) adjusted for bias of ultrasound measurements were $0.20 \mathrm{~cm}$ and $4.49 \mathrm{~cm}^{2}$ for UFAT and ULMA, respectively. Differences in SEP were observed for ULMA, but not UFAT, by year. These results indicate that ultrasound can be an accurate estimator of carcass traits in live cattle when measurements are taken by an experienced, well-trained technician, with only small differences in accuracy between years.
\end{abstract}

Key Words: Accuracy, Beef Cattle, Carcass Composition, Ultrasound

(C2003 American Society of Animal Science. All rights reserved.

J. Anim. Sci. 2003. 81:676-682

\section{Introduction}

The use of ultrasound technology to predict carcass traits in live cattle is not a new concept, as ultrasound has been used for over $40 \mathrm{yr}$ to determine body composition in live animals (Stouffer et al., 1959). Generally, most researchers have found ultrasound to estimate carcass fat with an acceptable degree of accuracy (Wallace et al., 1977; Brethour, 1992). Results for longissimus muscle area have been less conclusive (Smith et al., 1992; Waldner et al., 1992). Development of a longer ultrasound transducer designed specifically for cattle

\footnotetext{
${ }^{1}$ Correspondence and present address: Dept. of Animal and Poultry Sci., Virginia Tech, 366 Litton-Reaves Hall, Blacksburg 24061 (phone: 540-231-9159; fax: 540-231-3713; E-mail: sgreiner@vt.edu).

Received June 11, 2002.

Accepted November 22, 2002.
}

use that would allow for imaging of the entire longissimus muscle area, has resulted in improved accuracy of this trait (Herring et al., 1994).

Most studies have focused on the effects of animal, technician, and machine on ultrasound accuracy (McLaren et al., 1991; Perkins et al., 1992a; Herring et al., 1994). However, variation in ultrasound accuracy by the same technician scanning similar populations of cattle over time has not been investigated. Large differences in the accuracy of ultrasound in successive years has implications if producers are to make genetic progress by using this technology on breeding animals. Therefore, the objective of this study was to determine the relationship between ultrasound and carcass measures of 12th-rib fat and longissimus muscle area in a large population of genetically diverse cattle. Additionally, the effect of year on ultrasound accuracy when measurements were taken by an experienced, welltrained technician was evaluated. 


\section{Materials and Methods}

This study was conducted in cooperation with the Roman L. Hruska U.S. Meat Animal Research Center (MARC), Clay Center, NE. Five hundred thirty-four calf-fed steers from the 1993 (yr 1, n = 282) and 1994 (yr 2, n = 252) calf crops of Cycle V of the Germplasm Evaluation (GPE) program were used (Wheeler et al., 2001). Cycle $\mathrm{V} \mathrm{F}_{1}$ calves were produced by mating Hereford, Angus, and MARC III ( $1 / 4$ Red Poll, $1 / 4$ Hereford, $1 / 4$ Pinzgauer, $1 / 4$ Angus) dams to Hereford, Angus, Tuli, Boran, Belgian Blue, and Brahman bulls. Description of experimental cattle sources, animal management practices, and cattle harvest/processing are detailed in Wheeler et al. (2001). Carcass fat thickness used to assess ultrasound accuracy was an unadjusted measurement taken $3 / 4$ the length ventrally over the longissimus muscle (CFAT). Longissimus muscle areas (CLMA) were traced on acetate paper and measured later with a planimeter.

Each year, within $5 \mathrm{~d}$ of slaughter, steers were measured ultrasonically by the same Beef Improvement Federation (BIF, 1997) certified technician for fat thickness between the 12 th and 13 th ribs, $3 / 4$ the length ventrally over the longissimus muscle (UFAT), and for longissimus muscle area between the 12th and 13th ribs (ULMA). Images were also collected for rump fat thickness at the junction of the biceps femoris and gluteus medius between the ischium and illium and parallel to the vertebral column (URPFAT). Body wall thickness at the 12th- to 13th-rib interface was collected perpendicular to the external body surface at a distance of $4 \mathrm{~cm}$ from the ventral tip of the longissimus muscle (UBDWALL). Images were taken with an Aloka 500V real-time ultrasound machine (Corometrics Medical Systems, Wallingford, CT) equipped with a $17.2-\mathrm{cm}$, $3.5-\mathrm{MHz}$ linear transducer. To ensure proper contact between the ultrasound transducer and animal, the transducer was fitted with a Superflab (Mick RadioNuclear Instruments, Inc., Bronx, NY) guide for UFAT and ULMA image collection. In the area to be scanned, hair was clipped, thoroughly curried, and cleaned prior to image collection. Vegetable oil was used as a couplant to obtain adequate acoustic contact. Once a suitable image had been obtained, the image was digitized and stored on a personal computer with a video frame grabber. Only one image per animal was stored for each ultrasound trait. Images were interpreted using software developed at Iowa State University.

Statistical analyses were conducted using SAS (SAS Inst., Inc., Cary, NC). Pearson product moment correlation coefficients were used to evaluate the relationships between ultrasound and carcass measurements. Several variables were created to assess the accuracy of ultrasound measurements relative to carcass measurements (Table 1). Analysis of variance was also conducted for specific carcass measurement ranges so that accuracy of ultrasound measurements could be compared within the following six CFAT categories: 1)
Table 1. Description of acronyms

\begin{tabular}{ll}
\hline \hline Acronym & \multicolumn{1}{c}{ Definition } \\
\hline HCW & Hot carcass weight, kg \\
CFAT & Carcass 12th-rib fat thickness, cm \\
UFAT & Ultrasound 12th-rib fat thickness, cm \\
CLMA & Carcass longissimus muscle area, cm ${ }^{2}$ \\
ULMA & Ultrasound longissimus muscle area, cm ${ }^{2}$ \\
URPFAT & Ultrasound rump fat thickness, cm \\
UBDWALL & Ultrasound body wall thickness, cm \\
FDIFF & (UFAT - CFAT), cm \\
FDEV & |(UFAT - CFAT)|, cm \\
RDIFF & (ULMA - CLMA), cm ${ }^{2}$ \\
RDEV & |(ULMA - CLMA)|, cm \\
\hline
\end{tabular}

CFAT $\leq 0.51 \mathrm{~cm}$; 2) CFAT $>0.51$ and $\leq 0.76 \mathrm{~cm}$; 3) CFAT $>0.76$ and $\leq 1.02 \mathrm{~cm}$; 4) CFAT $>1.02$ and $\leq 1.27$ $\mathrm{cm}$; 5) CFAT $>1.27$ and $\leq 1.52 \mathrm{~cm}$; 6) CFAT $>1.52 \mathrm{~cm}$. Similarly, five CLMA categories were created: 1) CLMA $\leq 71.0 \mathrm{~cm}^{2}$; 2) CLMA > 71.0 and $\leq 77.4 \mathrm{~cm}^{2}$; 3) CLMA $>77.4$ and $\leq 83.9 \mathrm{~cm}^{2}$; 4) CLMA $>83.9$ and $\leq 90.3 \mathrm{~cm}^{2}$; and 5) CLMA $>90.3 \mathrm{~cm}^{2}$.

Standard errors of prediction, adjusted for mean bias in the subclass of interest, were also calculated for UFAT and ULMA. The standard error of prediction (SEP) is a statistic used to evaluate ultrasound technician accuracy in current ultrasound certification clinics (BIF, 1997).

\section{Results and Discussion}

Descriptions of the acronyms assigned to variables are presented in Table 1 . The ranges for carcass measurements were 214 to $463 \mathrm{~kg}$ for HCW, 0.25 to 2.79 $\mathrm{cm}$ for CFAT, and 43.2 to $111.6 \mathrm{~cm}^{2}$ for CLMA (Table $2)$. The standard deviation for CFAT $(0.44 \mathrm{~cm})$ was similar to values reported by Perkins et al. (1992b) and Herring et al. (1994). Because this study contained only steers, the CLMA standard deviation $\left(8.69 \mathrm{~cm}^{2}\right)$ was smaller than the $9.2 \mathrm{~cm}^{2}$ reported by Perkins et al. (1992a) and $9.6 \mathrm{~cm}^{2}$ reported by Duello (1992), both of whom utilized populations of mixed sexes.

Table 2. Means and standard deviations of carcass and ultrasound measures $(n=534)^{a}$

\begin{tabular}{lcc}
\hline \hline Trait & Mean & SD \\
\hline HCW, kg & 342.5 & 41.9 \\
CFAT, cm & 1.09 & 0.44 \\
UFAT, cm & 1.02 & 0.35 \\
CLMA, cm & 78.10 & 8.69 \\
ULMA, cm & 78.81 & 7.62 \\
URPFAT, cm & 1.09 & 0.32 \\
UBDWALL, cm & 5.36 & 0.82 \\
FDIFF, cm & $-0.06^{* * *}$ & 0.20 \\
FDEV, cm & 0.16 & 0.14 \\
RDIFF, cm & $0.71^{* * *}$ & 4.49 \\
RDEV, $\mathrm{cm}^{2}$ & 3.39 & 3.03 \\
\hline
\end{tabular}

asee Table 1 for description of acronyms.

$* * *$ Mean values different from zero $(P<0.001)$. 
Table 3. Correlation coefficients among ultrasound and carcass measurements $(n=534)^{a}$

\begin{tabular}{lcccccc}
\hline \hline Variable & CFAT & UFAT & CLMA & ULMA & URPFAT & UBDWALL \\
\hline CFAT & - & $0.89^{* * * *}$ & -0.14 & -0.04 & 0.61 & 0.53 \\
UFAT & & - & -0.20 & $-0.09^{*}$ & 0.70 & 0.57 \\
CLMA & & - & 0.86 & -0.09 & 0.14 \\
ULMA & & & - & -0.02 & 0.24 \\
URPFAT & & & & & - & 0.44 \\
UBDWALL & & & & & & - \\
\hline
\end{tabular}

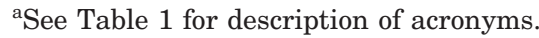

*Correlation coefficients with absolute values $\geq 0.09$ differ from zero $(P<0.05)$.

***Correlation coefficients with absolute values $\geq 0.14$ differ from zero $(P<0.001)$.

The correlations between carcass and ultrasound measurements of 12th-rib fat $(\mathrm{r}=0.89)$ and longissimus muscle area $(r=0.86)$ are in agreement with values reported for experienced, highly skilled technicians (Table 3). In a review of ultrasound accuracy studies, Houghton and Turlington (1992) reported average correlations of 0.86 and 0.73 between carcass and ultrasound measurements of 12th-rib fat and longissimus muscle area, respectively. Although Robinson et al. (1992) reported mean longissimus muscle area correlations of 0.88 to 0.90 for technicians achieving accreditation, the range of correlations for longissimus muscle area is generally more variable than 12th-rib fat thickness.

Although correlation coefficients are useful, they also have their limitations since they do not account for bias (tendency to underestimate or overestimate carcass measurement with ultrasound). Analysis of mean bias (FDIFF) revealed ultrasound underestimated CFAT by $0.06 \mathrm{~cm}$ for the entire population (Table 2). This value was larger in magnitude than the values reported by Duello (1992), Perkins et al. (1992a), and Robinson et al. (1992). All studies reported that UFAT measurements were less than CFAT measurements. Mean FDEV indicated an average absolute difference between UFAT and CFAT of $0.16 \mathrm{~cm}$. This value was similar to the results obtained by Brethour (1992; $0.157 \mathrm{~cm}$ ) and Per- kins et al. (1992a; $0.19 \mathrm{~cm})$, and lower than the 0.23 cm reported by Duello (1992).

In contrast to fat thickness measurements, ULMA measurements were larger $\left(0.71 \mathrm{~cm}^{2}\right)$ than CLMA measurements in this study. In contrast, Smith et al. (1992), Perkins et al. (1992b), and May et al. (2000) reported the tendency for ULMA to be smaller than CLMA. The mean absolute difference between ULMA and CLMA (RDEV, Table 2) was $3.31 \mathrm{~cm}^{2}$, which is more accurate than the range of 4.94 to $6.76 \mathrm{~cm}^{2}$ reported by Herring et al. (1994) for technicians using a machine identical to that used in the present study.

Analysis of variance revealed year to be a significant source of variation for ultrasound measurement variables (Table 4). Mean FDIFF and FDEV were larger $(P<0.01)$ in magnitude in yr 2 . These differences may be partially attributed to differences in CFAT since steers were leaner $(P<0.01)$ in yr 1 than yr 2 . Several studies have demonstrated that the magnitude of the difference between UFAT and CFAT increases as CFAT increases (Brethour, 1992; Duello, 1992; Herring et al., 1994). However, correlations between UFAT and CFAT were similar ( $\mathrm{r}=0.86$ and 0.90 , respectively) between years (Table 5).

Bias in ultrasound estimates of CLMA was not different between years $(P>0.10)$, even though RDIFF was numerically smaller in yr 2 . However, RDEV increased

Table 4. Means and standard deviations of carcass and ultrasound measures by year ${ }^{\mathrm{a}}$

\begin{tabular}{lcccc}
\hline \hline & \multicolumn{2}{c}{ Yr 1 $(\mathrm{n}=282)$} & \multicolumn{2}{c}{ Yr 2 $(\mathrm{n}=252)$} \\
\cline { 2 - 3 } Trait & Mean & SD & Mean & SD \\
\hline HCW, kg & 333.6 & 40.4 & 352.4 & 41.4 \\
CFAT, cm & 1.04 & 0.41 & 1.14 & 0.46 \\
UFAT, cm & 1.00 & 0.35 & 1.05 & 0.35 \\
CLMA, cm & 75.99 & 7.99 & 80.45 & 8.83 \\
ULMA, cm & 27.04 & 7.49 & 80.79 & 0.27 \\
URPFAT, cm & 1.04 & 0.32 & 1.15 & 0.32 \\
UBDWALL, cm & 5.21 & 0.75 & 5.53 & 0.21 \\
FDIFF, cm & $-0.04^{* * *}$ & 0.19 & $-0.09^{* * *}$ & 0.14 \\
FDEV, cm & 0.15 & 0.13 & 0.18 & 5.48 \\
RDIFF, cm & $1.05^{* * *}$ & 3.35 & 0.34 & 3.68 \\
RDEV, cm & 2.71 & 2.22 & 4.15 &
\end{tabular}

${ }^{\text {aSee Table }} 1$ for description of acronyms.

***Mean values different from zero $(P<0.001)$. 
Table 5. Correlation coefficients between ultrasound and carcass measurements by year ${ }^{\mathrm{a}}$

\begin{tabular}{|c|c|c|c|c|c|c|}
\hline Variable & CFAT & UFAT & CLMA & ULMA & URPFAT & UBDWALL \\
\hline \multicolumn{7}{|l|}{ Yr 1} \\
\hline CFAT & - & $0.86 \dagger$ & -0.21 & -0.13 & 0.59 & 0.57 \\
\hline UFAT & & - & -0.25 & -0.16 & 0.69 & 0.62 \\
\hline CLMA & & & - & 0.91 & -0.14 & 0.07 \\
\hline ULMA & & & & - & 0.10 & 0.15 \\
\hline URPFAT & & & & & - & 0.43 \\
\hline UBDWALL & & & & & & - \\
\hline \multicolumn{7}{|l|}{ Yr 2} \\
\hline CFAT & - & 0.90 & -0.15 & -0.01 & 0.63 & 0.48 \\
\hline UFAT & & - & -0.21 & -0.06 & 0.72 & 0.52 \\
\hline CLMA & & & - & 0.79 & -0.14 & 0.12 \\
\hline ULMA & & & & - & -0.03 & 0.25 \\
\hline URPFAT & & & & & - & 0.42 \\
\hline UBDWALL & & & & & & - \\
\hline
\end{tabular}

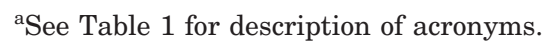

$\dagger$ Correlation coefficients with absolute values $\geq 0.10$ differ from zero $(P<0.10)$.

$(P<0.01)$ from $2.71 \mathrm{~cm}^{2}$ in yr 1 to $4.15 \mathrm{~cm}^{2}$ in $\mathrm{yr} 2$, indicating that ultrasound estimates of CLMA were more accurate in yr 1 . The stronger correlation between ULMA and CLMA in yr $1(\mathrm{r}=0.91)$ compared to yr 2 $(\mathrm{r}=0.79)$ supports this finding (Table 5). The larger $(P$ $<0.01$ ) mean CLMA in yr 2 may have contributed to the larger RDEV, as larger CLMA have been shown to be estimated less accurately with ultrasound (Duello, 1992; Herring et al., 1994).

To date, most ultrasound accuracy studies have examined the effects of operator, machine, and animal gender. Few have reported the effect of year using the same technician and machine on a population of similar cattle. Duello (1992) found year-to-year variation in ultrasound accuracy variables for both 12 th-rib fat and longissimus muscle area, although these effects could not be directly addressed because operator and machine were not consistent across the 3-yr study. The differences in accuracy noted between years in the present study may be due to technician error in collecting and interpreting images. Due to the length of this study, tendencies to deviate to one side or the other of anatomical reference points when interpreting UFAT and ULMA may have resulted in the differences observed between years. In addition, carcass measurements are not taken without error, and this could have an effect on the perceived accuracy of ultrasound. For example, Robinson et al. (1992) reported a difference of $1.3 \mathrm{~cm}^{2}$ between two CLMA tracers, presumably due to the tendency to deviate either to the inside or outside of the muscle boundary. Similarly, Rouse et al. (1992) obtained correlations of 0.97 for CFAT and 0.92 for CLMA between two carcass evaluators. Therefore, there are evaluator differences in carcass measurements that may have implications to the year effects reported in this study.

The SEP is a statistic used in certification clinics to accredit technicians for ultrasound proficiency (BIF, 1997). Robinson et al. (1992) states that this statistic has an advantage over mean absolute differences because by squaring differences, a few large errors are considered more serious than a greater number of small errors. The SEP also is thought to be the primary measure of the ability to correctly rank or predict differences between animals (Robinson et al., 1992).

The SEP for fat thickness (FSEP) and longissimus muscle area (RSEP) are presented in Table 6. Interestingly, FSEP was similar between years, although more bias was introduced in yr 2. Thus, after correction for bias, the FSEP data suggest that the accuracy of measuring CFAT with ultrasound was similar for the $2 \mathrm{yr}$. In contrast, RSEP was much smaller in yr 1 than yr 2 despite the smaller mean RDIFF obtained in yr 2. The RSEP would indicate that CLMA was more accurately estimated with ultrasound in yr 1.

As a comparison, Robinson et al. (1992) reported ranges of 0.07 to $0.13 \mathrm{~cm}$ and 4.94 to $5.16 \mathrm{~cm}^{2}$ for FSEP and RSEP, respectively, for technicians receiving accreditation. However, the cattle used by Robinson et al. (1992) had a mean CFAT of $0.45 \mathrm{~cm}$, which is much leaner than that reported in the present study. Moreover, Duello (1992) had a higher proportion of cattle with greater than $1.27 \mathrm{~cm}$ CFAT and obtained overall FSEP and RSEP of $0.29 \mathrm{~cm}$ and $6.25 \mathrm{~cm}^{2}$, respectively.

Earlier studies have questioned the use of ultrasound to assess CLMA (Smith et al., 1992; Waldner et al., 1992). The low RSEP of $4.49 \mathrm{~cm}^{2}$ achieved in the present study indicates that ultrasound can be used to accu-

Table 6. Standard errors of prediction for 12th- to 13thrib fat (FSEP) and longissimus muscle area (RSEP) by year

\begin{tabular}{lccc}
\hline \hline Year & $\mathrm{n}$ & FSEP, cm & RSEP, $\mathrm{cm}^{2}$ \\
\hline 1 & 282 & 0.19 & 3.35 \\
2 & 252 & 0.21 & 5.48 \\
Overall & 534 & 0.20 & 4.49 \\
\hline
\end{tabular}


Table 7. Least squares means and standard errors of accuracy variables by fat category ${ }^{\mathrm{a}}$

\begin{tabular}{lrcccc}
\hline \hline CFAT category & \multicolumn{1}{c}{$\mathrm{n}$} & FDIFF, cm & FDEV, cm & RDIFF, $\mathrm{cm}^{2}$ & RDEV, $\mathrm{cm}^{2}$ \\
\hline$\leq 0.51 \mathrm{~cm}$ & 58 & $0.106 \pm 0.022^{\mathrm{e}}$ & $0.138 \pm 0.017^{\mathrm{bc}}$ & $-0.91 \pm 0.53^{\mathrm{b}}$ & $2.87 \pm 0.39^{\mathrm{b}}$ \\
$>0.51$ and $\leq 0.76 \mathrm{~cm}$ & 121 & $0.038 \pm 0.015^{\mathrm{f}}$ & $0.125 \pm 0.012^{\mathrm{b}}$ & $-0.14 \pm 0.37^{\mathrm{bc}}$ & $3.44 \pm 0.27^{\mathrm{bc}}$ \\
$>0.76$ and $\leq 1.02 \mathrm{~cm}$ & 123 & $-0.045 \pm 0.015^{\mathrm{d}}$ & $0.125 \pm 0.012^{\mathrm{b}}$ & $0.12 \pm 0.37^{\mathrm{bc}}$ & $3.56 \pm 0.27^{\mathrm{bc}}$ \\
$>1.02$ and $\leq 1.27 \mathrm{~cm}$ & 109 & $-0.127 \pm 0.016^{\mathrm{c}}$ & $0.159 \pm 0.012^{\mathrm{cd}}$ & $0.11 \pm 0.40^{\mathrm{bc}}$ & $3.64 \pm 0.29^{\mathrm{bc}}$ \\
$>1.27$ and $\leq 1.52 \mathrm{~cm}$ & 56 & $-0.160 \pm 0.023^{\mathrm{c}}$ & $0.185 \pm 0.017^{\mathrm{d}}$ & $1.13 \pm 0.57^{\mathrm{cd}}$ & $4.22 \pm 0.41^{\text {cd }}$ \\
$>1.52 \mathrm{~cm}$ & 67 & $-0.307 \pm 0.021^{\mathrm{b}}$ & $0.299 \pm 0.016^{\mathrm{e}}$ & $1.46 \pm 0.51^{\mathrm{d}}$ & $4.47 \pm 0.37^{\mathrm{d}}$ \\
\hline
\end{tabular}

${ }^{\text {a See Table }} 1$ for description of acronyms.

b,c,d,e,f Means in a column with different superscripts differ $(P<0.05)$.

rately identify differences in CLMA between animals. The use of an ultrasonic transducer that allows the entire longissimus muscle cross-section to be imaged at once, compared to the split-screen technique required with shorter transducers used in earlier studies, likely contributed to the improvement in accuracy. Additionally, operator skill has been shown to have a strong influence on accuracy of ultrasonic estimation of carcass traits (Robinson et al., 1992; Waldner et al., 1992; Herring et al., 1994). The low FSEP and RSEP reported in the present study further emphasize the accuracy achievable by an experienced, well-trained technician. These values are appreciably smaller than the maximums of $0.30 \mathrm{~cm}$ (FSEP) and $7.74 \mathrm{~cm}^{2}$ (RSEP) established by the Beef Improvement Federation (BIF, 1997) for technician certification.

To assess differences in the accuracy of ultrasound as a result of the magnitude of the carcass measures, the data set was divided into six categories based on CFAT and five categories based on CLMA. Least squares means and standard errors of accuracy variables within these CFAT and CLMA categories are presented in Tables 7 and 8, respectively. Means of FDIFF by CFAT category indicate that leaner cattle $(<0.51 \mathrm{~cm}$ CFAT) were overestimated and fatter cattle $(>1.02 \mathrm{~cm}$ CFAT) were underestimated with ultrasound (Table 7). Least squares means of FDEV by CFAT category suggest the absolute difference between UFAT and CFAT was similar $(P>0.10)$ in categories with CFAT $<1.27 \mathrm{~cm}$, increased $(P<0.05)$ slightly when CFAT was between 1.27 and $1.52 \mathrm{~cm}$, and substantially increased $(P<0.05)$ when CFAT $>1.52 \mathrm{~cm}$. In contrast to the findings of Duello (1992), CFAT category influenced the accuracy of ULMA. Table 7 suggests that ultrasound underestimates CLMA in leaner cattle $(<0.51 \mathrm{~cm}$ CFAT) and has the opposite effect in fatter cattle $(>1.27 \mathrm{~cm}$ CFAT). Additionally, RDEV tended to increase $(P<$ 0.05) as CFAT increased. These results would support the theory that increased subcutaneous fat cover makes it more difficult to obtain a clear, high-quality image, particularly for the ventral portion of the image. As a result, determination of longissimus muscle boundaries becomes difficult and, therefore, reduces the accuracy of the ultrasound measurement.

Similarly, RDIFF showed that ultrasound overestimates CLMA in light-muscled steers $\left(<77.4 \mathrm{~cm}^{2}\right.$ CLMA) and underestimates CLMA in heavy-muscled steers (>83.9 $\mathrm{cm}^{2}$ CLMA; Table 8). Mean RDEV was largest $(P<0.10)$ for animals with very small $\left(<71.0 \mathrm{~cm}^{2}\right)$ and very large $\left(>90.3 \mathrm{~cm}^{2}\right)$ CLMA. These results agree with statistical expectations and previous studies that have examined bias of ultrasound measurements in different CFAT and CLMA categories (Smith et al., 1992; Herring et al., 1994).

Standard errors of prediction by CFAT and CLMA category are presented in Table 9 . These results generally agree with the DIFF and DEV variables previously discussed. Although the differences were small, FSEP tended to increase as CFAT increased. The greatest RSEP were associated with CLMA $<71.0$ and $>90.3$ $\mathrm{cm}^{2}$, with the smallest RSEP observed for the 83.9 to $90.3 \mathrm{~cm}^{2}$ CLMA category. The increase in RSEP as magnitude of CFAT increased further supports the hypothesis that accurate assessment of longissimus muscle

Table 8. Least squares means and standard errors of accuracy variables

by longissimus muscle area category ${ }^{\mathrm{a}}$

\begin{tabular}{lrrr}
\hline \hline CLMA category & $\mathrm{n}$ & RDIFF, $\mathrm{cm}^{2}$ & RDEV, $\mathrm{cm}^{2}$ \\
\hline$\leq 71.0 \mathrm{~cm}^{2}$ & 92 & $3.42 \pm 0.43^{\mathrm{b}}$ & $4.26 \pm 0.31^{\mathrm{h}}$ \\
$>71.0$ and $\leq 77.4 \mathrm{~cm}^{2}$ & 168 & $1.69 \pm 0.32^{\mathrm{c}}$ & $3.10 \pm 0.23^{\mathrm{i}}$ \\
$>77.4$ and $<83.9 \mathrm{~cm}^{2}$ & 144 & $0.55 \pm 0.34^{\mathrm{d}}$ & $2.93 \pm 0.25^{\mathrm{i}}$ \\
$>83.9$ and $\leq 90.3 \mathrm{~cm}^{2}$ & 81 & $-1.56 \pm 0.46^{\mathrm{e}}$ & $2.99 \pm 0.34^{\mathrm{i}}$ \\
$>90.3 \mathrm{~cm}^{2}$ & 49 & $-2.61 \pm 0.59^{\mathrm{f}}$ & $5.22 \pm 0.43^{\mathrm{g}}$ \\
\hline
\end{tabular}

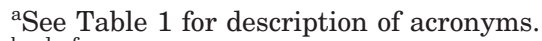

b,c,d,e,fMeans in a column with different superscripts differ $(P<0.05)$.

${ }^{\mathrm{g}, \mathrm{h}, \mathrm{i}}$ Means in a column with different superscripts $\operatorname{differ}(P<0.10)$. 
Table 9. Standard errors of prediction by 12th- to 13th-rib fat (FSEP) and longissimus muscle area (RSEP) categories ${ }^{\text {a }}$

\begin{tabular}{lrcc}
\hline \hline Category & $\mathrm{n}$ & FSEP, cm & RSEP, $\mathrm{cm}^{2}$ \\
\hline CFAT & & & \\
$\leq 0.51 \mathrm{~cm}$ & 58 & 0.16 & 3.75 \\
$>0.51$ and $\leq 0.76 \mathrm{~cm}$ & 121 & 0.16 & 4.36 \\
$>0.76$ and $\leq 1.02 \mathrm{~cm}$ & 123 & 0.15 & 4.21 \\
$>1.02$ and $\leq 1.27 \mathrm{~cm}$ & 109 & 0.17 & 4.49 \\
$>1.27$ and $\leq 1.52 \mathrm{~cm}$ & 56 & 0.18 & 4.25 \\
$>1.52 \mathrm{~cm}$ & 67 & 0.20 & 5.26 \\
CLMA & & & \\
$\leq 71.0 \mathrm{~cm}$ & 92 & 0.20 & 4.83 \\
$>71.0$ and $\leq 77.4 \mathrm{~cm}^{2}$ & 168 & 0.21 & 3.82 \\
$>77.4$ and $\leq 83.9 \mathrm{~cm}^{2}$ & 144 & 0.22 & 3.79 \\
$>83.9$ and $\leq 90.3 \mathrm{~cm}^{2}$ & 81 & 0.18 & 2.86 \\
$>90.3 \mathrm{~cm}^{2}$ & 49 & 0.16 & 5.52 \\
\hline
\end{tabular}

${ }^{\text {asee Table }} 1$ for description of acronyms.

area becomes more difficult in cattle with more fat cover.

Also of interest in this study were the characterizations of URPFAT and UBDWALL, which have been identified as additional measurements that may be useful in predicting beef carcass composition (Cross et al., 1973; Wallace et al., 1977; Williams et al., 1997). Means and ranges for URPFAT and UBDWALL were $1.09 \mathrm{~cm}$ $(0.30$ to $2.29 \mathrm{~cm})$ and $5.36 \mathrm{~cm}(3.34$ to $8.43 \mathrm{~cm})$, respectively (Table 2). Table 3 indicates that both URPFAT and UBDWALL were positively related to CFAT and UFAT. As with CFAT and UFAT, mean URPFAT and UBDWALL measurements increased $(P<0.01)$ across years (Table 4), and correlations of URPFAT with CFAT and UFAT were consistent across year (Table 5). However, UBDWALL was more strongly related to both CFAT and UFAT in yr 1. The reason for this difference is not known; however, it is possible that there may have been some inconsistencies in image interpretation that occurred between years, such as those discussed earlier for UFAT and ULMA. The correlation between URPFAT and UBDWALL $(\mathrm{r}=0.44)$ indicates these two traits are moderately related.

Least squares means and SE of URPFAT and UBDWALL by CFAT category are presented in Table 10 . Results indicate that both traits increased as CFAT and UFAT increased. Of interest is the mean URPFAT compared to CFAT and UFAT for each category. In cattle with $<1.02 \mathrm{~cm}$ CFAT, URPFAT mean exceeded both CFAT and UFAT. It has been proposed that URPFAT could serve as an alternative measurement site for subcutaneous fat in leaner cattle (breeding cattle) because URPFAT is greater than CFAT; therefore, differences between animals could more easily be measured with ultrasound.

Because rump fat measurements are difficult to obtain on the carcass, accuracy measures for URPFAT are not available in this study. Robinson et al. (1992) reported rump fat depth measured with ultrasound to be consistently $20 \%$ higher than carcass measurements, and accuracy measures for rump fat were similar to those found for 12th-rib fat. The ultrasonic rump fat measure used by Robinson et al. (1992) was at the P8 site, located over the gluteus medius on the rump, which is similar to, but not precisely, the location used for URPFAT in this study. The P8 site does not have an obvious reference point, whereas the rump fat site in the present study uses a muscle junction to ensure consistent placement of the transducer.

\section{Implications}

Results from this study indicate that ultrasound technology has the potential to determine fat thickness and

Table 10. Least squares means and standard errors of rump fat and body wall thickness by fat category ${ }^{a}$

\begin{tabular}{lrcccc}
\hline \hline CFAT category & \multicolumn{1}{c}{$\mathrm{n}$} & CFAT, cm & UFAT, cm & URPFAT, cm & UBDWALL, cm \\
\hline$\leq 0.51 \mathrm{~cm}$ & 58 & $0.47 \pm 0.014^{\mathrm{b}}$ & $0.58 \pm 0.022^{\mathrm{ba}}$ & $0.76 \pm 0.033^{\mathrm{ba}}$ & $4.65 \pm 0.089^{\mathrm{h}}$ \\
$>0.51$ and $\leq 0.76 \mathrm{~cm}$ & 121 & $0.73 \pm 0.010^{\mathrm{c}}$ & $0.76 \pm 0.015^{\mathrm{c}}$ & $0.93 \pm 0.023^{\mathrm{c}}$ & $5.02 \pm 0.063^{\mathrm{i}}$ \\
$>0.76$ and $\leq 1.02 \mathrm{~cm}$ & 123 & $0.97 \pm 0.010^{\mathrm{d}}$ & $0.93 \pm 0.015^{\mathrm{d}}$ & $1.06 \pm 0.023^{\mathrm{d}}$ & $5.32 \pm 0.062^{\mathrm{j}}$ \\
$>1.02$ and $\leq 1.27 \mathrm{~cm}$ & 109 & $1.23 \pm 0.010^{\mathrm{e}}$ & $1.10 \pm 0.016^{\mathrm{e}}$ & $1.15 \pm 0.025^{\mathrm{e}}$ & $5.56 \pm 0.066^{\mathrm{k}}$ \\
$>1.27$ and $\leq 1.52 \mathrm{~cm}$ & 56 & $1.47 \pm 0.015^{\mathrm{f}}$ & $1.31 \pm 0.023^{\mathrm{f}}$ & $1.32 \pm 0.035^{\mathrm{f}}$ & $5.93 \pm 0.095^{\mathrm{l}}$ \\
$>1.52 \mathrm{~cm}$ & 67 & $1.92 \pm 0.013^{\mathrm{g}}$ & $1.61 \pm 0.021^{\mathrm{g}}$ & $1.44 \pm 0.032^{\mathrm{g}}$ & $6.20 \pm 0.086^{\mathrm{m}}$ \\
\hline
\end{tabular}

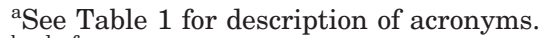

b,c,d,e,f,g,Means in a column with different superscripts differ $(P<0.01)$.

h,i, , , , , l, m Means in a column with different superscripts differ $(P<0.05)$. 
longissimus muscle area with a high degree of accuracy when done by an experienced, well-trained technician. Therefore, ultrasound can be used to describe carcass traits in live cattle and allow for selection and management decisions. Differences in accuracy for ultrasonic measurements across years emphasize the importance of proper maintenance of technique by technicians and the need for periodic proficiency testing. The strong relationship between ultrasonic measurements of rump fat and body wall thickness with carcass 12th-rib fat thickness suggest the need to further investigate these variables as additional indicators of composition.

\section{Literature Cited}

BIF. 1997. Proc. 29th Annu. Mtg. of the Beef Improv. Fed., Dickinson, ND.

Brethour, J. R. 1992. The repeatability and accuracy of ultrasound in measuring backfat in cattle. J. Anim. Sci. 70:1039-1044.

Cross, H. R., Z. L. Carpenter, and G. C. Smith. 1973. Equations for estimating boneless retail cut yields from beef carcasses. J. Anim. Sci. 37:1267-1272.

Duello, D. A. 1993. The use of real-time ultrasound measurements to predict composition and estimate genetic parameters of carcass traits in live beef cattle. Ph.D. Thesis. Iowa State Univ., Ames.

Herring, W. O., D. C. Miller, J. K. Bertrand, and L. L. Benyshek. 1994. Evaluation of machine, technician, and interpreter effects on ultrasonic measures of backfat and longissimus muscle area in beef cattle. J. Anim. Sci. 72:2216-2226.

Houghton, P. L., and L. M. Turlington. 1992. Application of ultrasound for feeding and finishing animals: A review. J. Anim. Sci. 70:930-941.

May, S. G., W. L. Mies, J. W. Edwards, J. J. Harris, J. B. Morgan, R. P. Garrett, F. L. Williams, J. W. Wise, H. R. Cross, and J. W. Savell. 2000. Using live estimates and ultrasound measurements to predict beef carcass cutability. J. Anim. Sci. 78:1255-1261.

McLaren, D. G., J. Novakofski, D. F. Parrett, L. L. Lo, S. D. Singh, K. R. Neumann, and F. K. McKeith. 1991. A study of operator effects on ultrasonic measures of fat depth and longissimus muscle area in cattle, sheep and pigs. J. Anim. Sci. 69:54-66.

Perkins, T. L., R. D. Green, and K. E. Hamlin. 1992a. Evaluation of ultrasonic estimates of carcass fat thickness and longissimus muscle area in beef cattle. J. Anim. Sci. 70:1002-1010.

Perkins, T. L., R. D. Green, K. E. Hamlin, H. H. Shepard, and M. F. Miller. 1992b. Ultrasonic prediction of carcass merit in beef cattle: Evaluation of technician effects on ultrasonic estimates of carcass fat thickness and longissimus muscle area. J. Anim. Sci. 70:2758-2765.

Robinson, D. L., C. A. McDonald, K. Hammond, and J. W. Turner. 1992. Live animal measurement of carcass traits by ultrasound: Assessment and accuracy of sonographers. J. Anim. Sci. 70:1667-1676.

Rouse, G., D. Wilson, D. Duello, and B. Reiling. 1992. The accuracy of real-time ultrasound scans taken serially on small-, medium, and large-framed steers and bulls slaughtered at three endpoints. 1992 Iowa State Univ. Beef and Sheep Res. Rep. A. S. Leaflet R896, Ames.

Smith, M. T., J. W. Oltjen, H. G. Dolezal, D. R. Gill, and B. D. Behrens. 1992. Evaluation of ultrasound for prediction of carcass fat thickness and longissimus muscle area in feedlot steers. J. Anim. Sci. 70:29-37.

Stouffer, J. R., M. V. Wellentine, and G. H. Wellington. 1959. Ultrasonic measurement of fat thickness and loin eye area on live cattle and hogs. J. Anim. Sci. 18:1483. (Abstr.)

Waldner, D. N., M. E. Dikeman, R. R. Schalles, W. G. Olson, P. L. Houghton, J. A. Unruh, and L. R. Corah. 1992. Validation of real-time ultrasound technology for predicting fat thickness, longissimus muscle areas, and composition of Brangus bulls from 4 months to 2 years of age. J. Anim. Sci. 70:3044-3054.

Wallace, M. A., J. R. Stouffer, and R. G. Westervelt. 1977. Relationships of ultrasonic and carcass measurements with retail yield in beef cattle. Livest. Prod. Sci. 4:153-164.

Wheeler, T. L., L. V. Cundiff, S. D. Shackelford, and M. Koohmaraie. 2001. Characterization of biological types of cattle (Cycle V): Carcass traits and longissimus palatability. J. Anim. Sci. 79:1209-1222.

Williams, R. E., J. K. Bertrand, S. E. Williams, and L. L. Benyshek. 1997. Biceps femoris and rump fat as additional ultrasound measurements for predicting retail product and trimmable fat in beef carcasses. J. Anim. Sci. 75:7-13. 